Article

\title{
Fungal Growth on Coated Wood Exposed Outdoors: Influence of Coating Pigmentation, Cardinal Direction, and Inclination of Wood Surfaces
}

\author{
Laurence Podgorski *, Céline Reynaud and Mathilde Montibus \\ FCBA Technological Institute, Allée de Boutaut BP227, Bordeaux F-33028, France; celine.reynaud@fcba.fr (C.R.); \\ mathilde.montibus@fcba.fr (M.M.) \\ * Correspondence: laurence.podgorski@fcba.fr; Tel.: +33-556-436-366
}

Received: 21 November 2018; Accepted: 21 December 2018; Published: 4 January 2019

check for updates

\begin{abstract}
Four coating systems were exposed for one year outdoors at $45^{\circ}$ south. They consisted of solventborne (alkyd based) and waterborne (acrylic based) systems in both clear and pigmented versions. Fungal growth visually assessed was compared to fungal enumeration, and the influence of exposure time on the main fungal species was studied. Results clearly showed that fungal growth was lower on the pigmented coating systems compared with their pigment-free versions. Although the clear solventborne coating included a higher amount of biocide, it was more susceptible to blue stain than the pigmented version. A new multifaceted exposure rig (MFER) also contributed to the study of fungal growth. It allowed samples to be exposed with nine different exposure directions and angles. Exposure using this MFER has shown that the worst cases (highest area and intensity of blue stain fungi) were for samples with the clear coating system exposed to north $45^{\circ}$ and at the top of the MFER (horizontal surfaces). For any cardinal direction, all surfaces inclined at $45^{\circ}$ displayed more blue stain fungi than vertical surfaces, due to a higher moisture content of the panels. Depending on the cardinal direction and the orientation, some surfaces were free of visible cracking, but colonized by fungi. It was concluded that the growth of blue stain fungi was not linked with cracking development.
\end{abstract}

Keywords: coating; wood; weathering; fungi; blue stain; molds; cracking; pigments

\section{Introduction}

Surface fungi or molds grow on most carbon-containing materials including wood, paint, and clear coatings [1-3]. Fungal growth, and especially blue stain fungi on exterior wood coatings are considered to be a major maintenance concern. In addition to reducing the aesthetics of surfaces of buildings, blue stain may also shorten the service life of coatings: when blue stain fungi develop on coated surfaces, the hyphae create pinholes in the coatings, and therefore contribute to coating film disruption [4]. These pinholes are pathways for moisture ingress, leading to the possible decay of building components. Avoiding blue stain is possible by using fungicides in the coating. However, due to the Biocidal Products Regulation, anti-blue stain fungicides are less and less being used in coatings [5,6]. This leads to surface coatings on buildings with a higher amount of fungal growth. Modern heat insulation also contributes to mold growth, as surfaces remain damp for longer periods [6,7]. Several studies have reported that coating formulation and especially pigmentation influence fungal growth $[4,8-10]$. It was shown that brown semi-transparent coatings were less sensitive to blue stain than white paints [9].

Fungal growth is overlooked in the performance criteria of coating systems (EN 927-2), which is based on the mandatory assessment of blistering, cracking, flaking, and adhesion after 12 months of natural weathering [11]. Blistering is the sign of a lack of water-vapor transmission through the coating 
film. However, it is rarely noticed with the present waterborne coatings, which have higher moisture permeabilities in comparison to solventborne alternatives [4]. Therefore, amongst these performance criteria, the first sign of coating degradation is cracking. It subsequently leads to flaking and loss of adhesion. According to some authors, blue stain fungi in service are considered not to originate from spores that are already present in the wood, but from penetration through defects in the paint film or insufficiently protected surfaces [4]. However, the relationship between fungal growth and cracking development is still unclear.

Therefore, the objective of this paper was to study the influence of coating pigmentation, cardinal direction, and exposure angle on fungal growth of field-exposed panels, with special attention to the sequence between fungal growth and cracking development. Four coating systems were exposed for one year outdoors at $45^{\circ}$ south. They consisted of solventborne (alkyd based) and waterborne (acrylic based) systems, in both clear and pigmented versions. This paper compares visually assessed fungal growth to fungal enumeration. The influence of exposure time on the main fungal species was studied. A new multifaceted exposure rig (MFER) also contributed to the study of fungal growth versus the cardinal orientation and angle of exposure $\left(45^{\circ}, 90^{\circ}, 0^{\circ}\right)$.

\section{Materials and Methods}

\subsection{Coatings}

Four coatings (two acrylics and two alkyds) described in Table 1 were used. The alkyd coatings (ICP strsp and ICP clear) were based on the Internal Comparison Product (ICP) defined in EN 927-3 [12]. The semi-transparent ICP (ICP strsp) was pigmented, whereas the ICP clear did not include any pigments (Table 2).

Semi-transparent and a clear waterborne formulations, equivalent in pigment volume concentration to the solvent-borne ICP formulations, were designed (WbAcry trsp and WbAcry clear). The acrylic coatings were based on a styrene acrylic emulsion (Table 3).

Table 1. Description of the four tested coatings.

\begin{tabular}{ccc}
\hline Coating Reference & Type of Coating & Pigmentation \\
\hline ICP strsp & Solventborne ICP & Semi-transparent \\
ICP clear & Solventborne ICP & Clear \\
WbAcry trsp & Waterborne acrylic & Semi-transparent \\
WbAcry clear & Waterborne acrylic & Clear \\
\hline
\end{tabular}

Table 2. Description of the solventborne Internal Comparison Product (ICP) in its semi-transparent (ICP strsp) and clear (ICP clear) versions.

\begin{tabular}{ccc}
\hline Components & ICP Strsp (wt \%) & ICP Clear (wt \%) \\
\hline Synolac 6005 WD 65 & 52.82 & 52.93 \\
Sicoflush red L2817 & 4.63 & - \\
Sicoflush yellow L1916 & 2.30 & - \\
Bentone 34 & 0.60 & 0.65 \\
Octa-Solingen Calcium 10 & 2.77 & 2.99 \\
Octa-Solingen Cobalt 10 & 0.37 & 0.40 \\
Octa-Solingen Zirconium 18 & 0.30 & 0.32 \\
Omacide IPBC & 0.72 & 1.00 \\
Tinuvin 292 & 0.45 & 0.49 \\
Troysan Anti-skin B & 0.20 & 0.22 \\
Shellsol D40 & 34.84 & 41.00 \\
Total & 100.00 & 100.00 \\
\hline
\end{tabular}


Table 3. Description of the waterborne acrylic coatings.

\begin{tabular}{ccc}
\hline Components & WbAcry Trsp (wt \%) & WbAcry Clear (wt \%) \\
\hline DSM Neocryl XK188 & 86.0 & 89.7 \\
Water & 2.0 & 2.0 \\
BASF Luconyl 1916 yellow & 2.4 & - \\
BASF Luconyl 2817 red & 1.2 & - \\
BASF Luconyl 0060 black & 0.1 & - \\
Ammonia 25\% & 0.1 & 0.1 \\
Ethyldiglycol & 5.0 & 5.0 \\
BASF Lusolvan FBH & 1.0 & 1.0 \\
BASF Dehydran 1293 & 0.5 & 0.5 \\
Dow Rocima 250 & 1.25 & 1.25 \\
Munzing Tafigel PUR 45 & 0.45 & 0.45 \\
Total & 100.00 & 100.00 \\
\hline
\end{tabular}

\subsection{Wood Samples}

Scots pine sapwood samples fulfilling the requirements of EN 927-3 [12] were selected. They were free from knots, cracks, and resinous streaks. Their dimensions were $375 \mathrm{~mm}(L), 75 \mathrm{~mm}(R), 20 \mathrm{~mm}(T)$. The mean density was $522 \mathrm{~kg} / \mathrm{m}^{3}$. The inclination of the growth rings to the face was $5^{\circ}$ to $45^{\circ}$. They were coated with the four coatings using brushes made of a blend of natural and synthetic bristles (DEXTER). For natural weathering tests (south exposure at $45^{\circ}$ ), three layers were applied. The wet spreading rate was $50 \mathrm{~g} / \mathrm{m}^{2}$ per layer.

For natural weathering using the multifaceted exposure rig (MFER), the dimensions of samples were $175 \mathrm{~mm}(L), 75 \mathrm{~mm}(R), 20 \mathrm{~mm}(T)$ with the same wood characteristics as above. Samples were covered with two coatings: ICP clear and WbAcry trsp, both brush-applied in two and three layers, with the same characteristics and spreading rate as before. Uncoated wood samples were also prepared as controls.

\subsection{Natural Weathering Test}

The samples coated with the four coating systems were exposed for one year (March 2015 to March 2016) at the exposure site of FCBA in Bordeaux (France), on racks facing south and inclined at $45^{\circ}$ according to EN 927-3 [12]. For each coating system, three replicates were tested. Uncoated wood samples were also exposed as controls. On these samples, visual assessment of fungal growth as well as fungal enumeration were carried out after 3, 6, 9, and 12 months. Panels were also weighed at each exposure time. The mass obtained was compared with the initial mass conditioned at $20{ }^{\circ} \mathrm{C}$ and $65 \%$ of relative humidity and corresponding to a theoretical moisture content of $12 \%$.

In addition, a multifaceted exposure rig (MFER) shown in Figure 1 was used. It was made of MONOLUX ${ }^{\circledR} 500$ boards, and was manufactured by PRA (Melton Mowbray, UK) for this study. Its length, width, and height were 1190, 1190, and $1000 \mathrm{~mm}$, respectively. It allowed samples to be exposed to four directions (south, west, north, and east) with two inclinations $\left(45^{\circ}\right.$ and $\left.90^{\circ}\right)$. The top of the MFER allowed samples to be exposed horizontally $\left(0^{\circ}\right)$. For each coating system, orientation and inclination, three replicates were used. The samples were exposed for one year (August 2015 to August 2016) at the exposure site of FCBA (Bordeaux, France) and visual assessment of fungal growth was carried out after 3, 6, 9, and 12 months of exposure. 


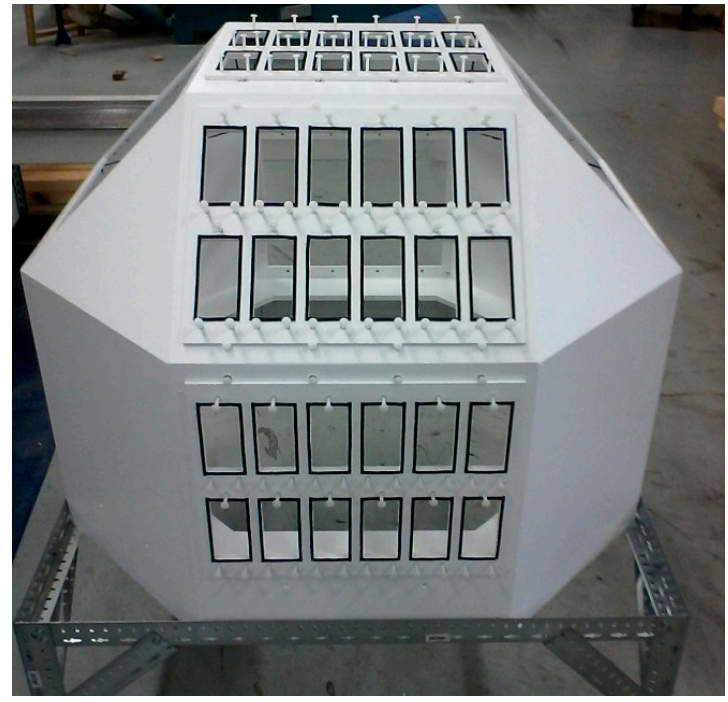

(a)

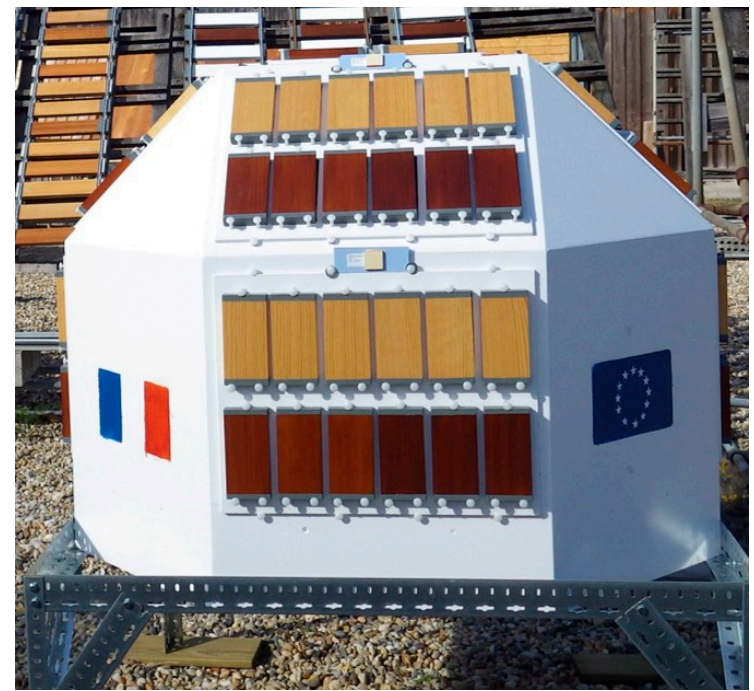

(b)

Figure 1. The multifaceted exposure rig (MFER) without (a) and with samples (b).

\subsection{Visual Assessment of Fungal Growth}

After each exposure time, the fungal growth and the intensity of development were assessed according to EN 16492 [13].

\subsection{Fungal Enumeration on Wood Panels}

For fungal analysis, two kinds of enumeration were performed:

- a surface analysis

- $\quad$ an in-depth analysis

For surface analysis, a central surface $(50 \mathrm{~mm} \times 40 \mathrm{~mm})$ of each panel was rubbed using a sterile swab moistened with water. The swab was then blended using a Stomacher ${ }^{\circledR} 80$ (Seward, UK) in $5 \mathrm{~mL}$ of sterile water with $\mathrm{NaCl} 0.9 \%$ for $1 \mathrm{~min}$. The recovery solutions were inoculated, sowing $100 \mu \mathrm{L}$ of serial dilutions on malt/agar. After incubation at $22{ }^{\circ} \mathrm{C}$ for $72 \mathrm{~h}$, the enumeration of colonies was undertaken.

For in-depth analysis, the exposed surfaces were cut off from each panel within a thickness of four millimeters; they were sawn, comminuted for $10 \mathrm{~s}$, and then comminuted for another $10 \mathrm{~s}$ in $25 \mathrm{~mL}$ of sterile water with $\mathrm{NaCl}$ 0.9\%. The recovery solutions were inoculated, sowing $100 \mu \mathrm{L}$ of serial dilutions onto malt/agar. After incubation at $22{ }^{\circ} \mathrm{C}$ for $72 \mathrm{~h}$, the enumeration of colonies was undertaken. Then, for each sample, the number of colony forming units (CFU) was calculated per $\mathrm{cm}^{2}$, and the results were then transformed into $\log _{10}$ scale $\left(1 \mathrm{LOG}\left(\mathrm{CFU} / \mathrm{cm}^{2}\right)=10 \mathrm{CFU} / \mathrm{cm}^{2}\right)$.

Fungal enumeration was performed on samples exposed for 3,6 , 9, and 12 months of south exposure at $45^{\circ}$.

The main fungal species growing after enumeration on panels were isolated for identification.

\subsection{Fungal Identification}

Fungal identification was achieved using microscopy by mycologists at FCBA. In addition, molecular identification was performed by DNA analysis. DNA extraction was made using the DNeasy plant extraction kit according to the manufacturer's instructions (QIAGEN, Hilden, Germany). PCR amplification was performed using the DreamTaq Hot Start DNA Polymerase, according to the manufacturer's instruction (Thermo Fisher Scientific, Waltham, MA, USA). ITS primers were used as described by Gardes and Bruns [14]. 
Sequencing was performed by GATC (Konstanz, Germany). Results were compared with the NCBI databases.

\subsection{Cracking}

The quantity of cracks in the coating systems was assessed after 12 months of exposure using the MFER, and rated from 0 (no detectable cracks) to 5 (dense pattern of cracks) using ISO 4628-4 [15].

\section{Results}

\subsection{Fungal Growth}

The area and the intensity of growth versus exposure time are presented in Figures 2 and 3, respectively. The fungal growth was visually identified as a blue stain.

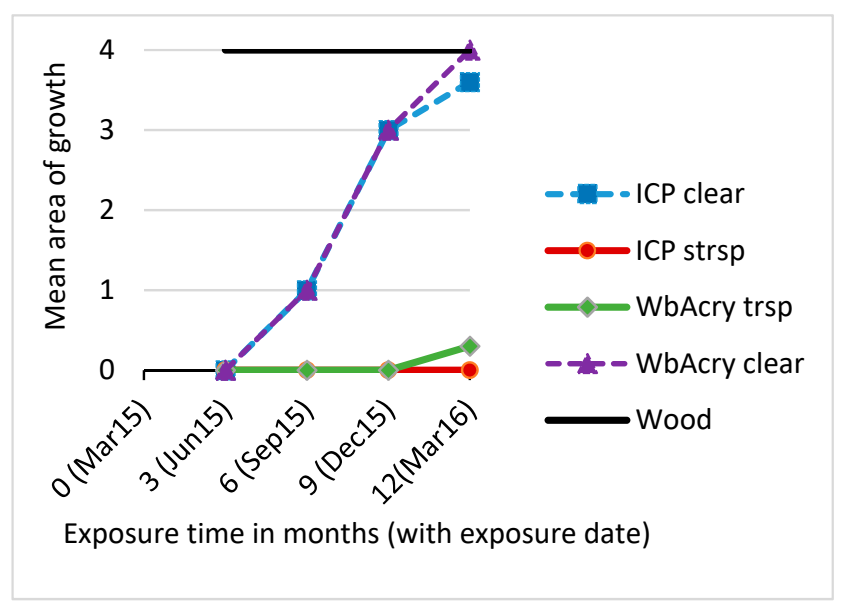

Figure 2. Mean area of fungal growth (EN 16 492) on panels versus exposure time.

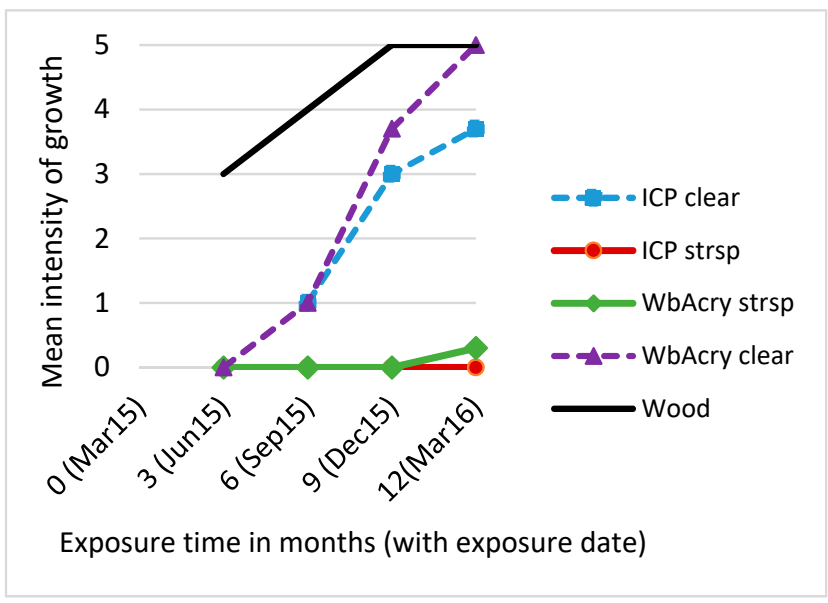

Figure 3. Intensity of fungal growth (EN 16492$)$ on panels versus exposure time.

Figure 2 shows that for uncoated wood, fungal growth was maximum (rating of 4) starting at 3 months of exposure. For coated wood, a strong difference existed between clear and semi-transparent coating systems. For clear coatings, a rating of 1 was reached after six months of exposure and a rating of 4 , similar to wood, was achieved after 12 months of exposure. For pigmented coatings, the rating of 1 was not reached after 12 months of exposure.

Results clearly showed that lower fungal growth was observed on the pigmented coating systems. For the solventborne coatings, the amount of biocide in the recipe was a little bit higher for the clear coating (ICP clear) compared with the pigmented coating (ICP strsp). Despite this higher amount, the 
clear coating (ICP clear) was more susceptible to blue stain fungi than the pigmented recipe. In the waterborne coatings (WbAcry trsp and WbAcry clear), the amount of biocide was the same, whether the coating was pigmented or not. However, the pigmented waterborne coating system was less prone to blue stain development.

As shown in Figure 3, the intensity of growth for uncoated wood ranged from 3 to 5 . For coated wood, a strong difference in the intensity of growth was found between the clear and semi-transparent coating systems. For both clear coating systems, the rating of 1 was reached after six months of exposure. The rating exceeded 3 after 12 months of exposure for the clear ICP, and reached 5 for the clear acrylic coating. For both pigmented coatings (ICP strsp and WbAcry trsp), the rating of 1 was not reached after 12 months of exposure. Results demonstrated that a lower intensity of growth was observed on the pigmented coating systems.

\subsection{Fungal Enumeration}

The results of fungal enumeration for surface and in-depth analysis are presented in Figures 4 and 5 , respectively.

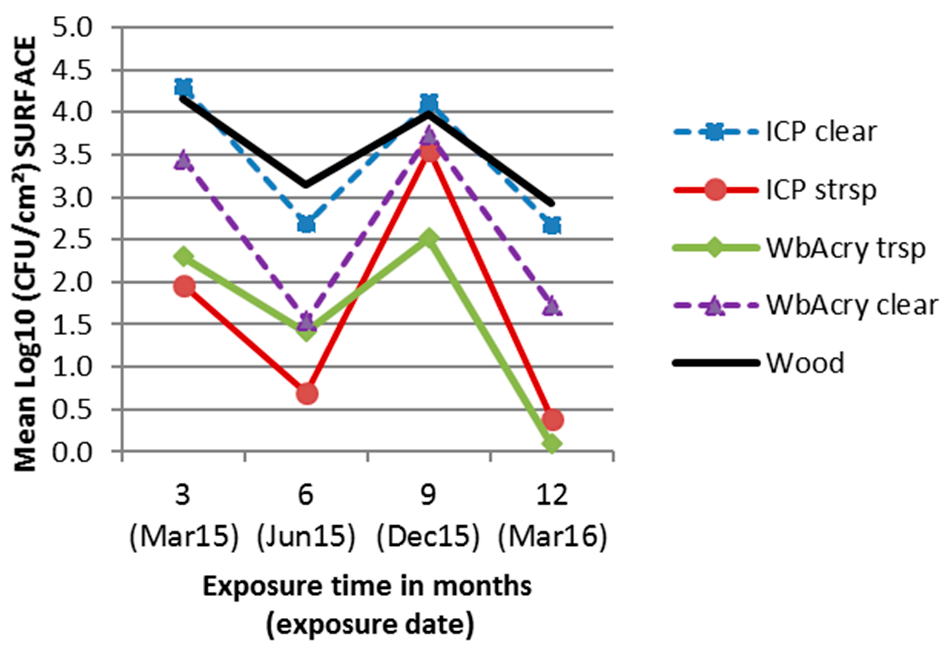

Figure 4. Surface fungal enumeration of panels versus exposure time.

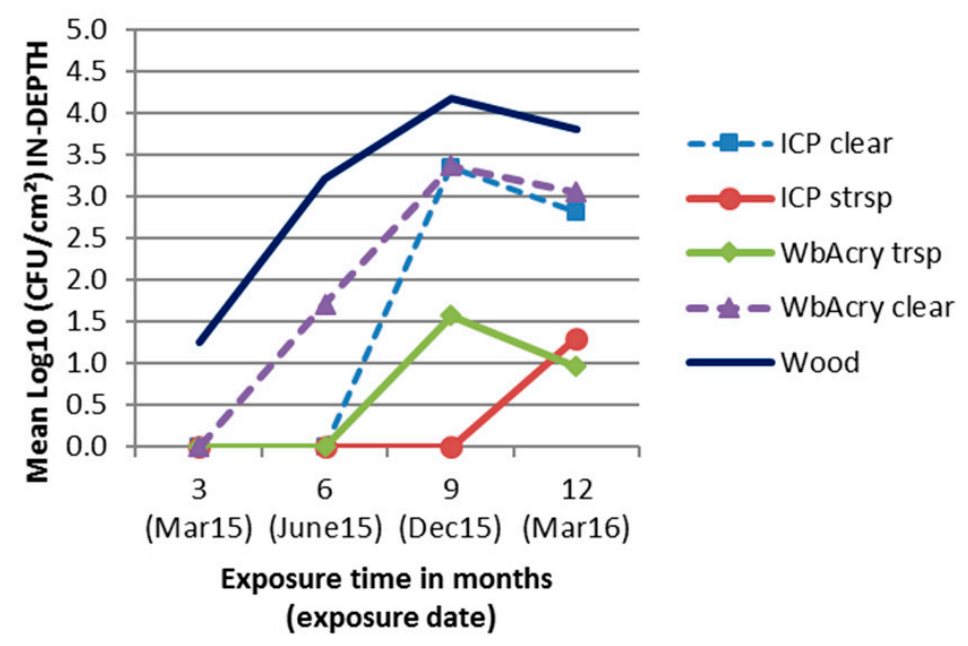

Figure 5. In-depth fungal enumeration of panels versus exposure time.

These figures show that results were different for surface analysis and in-depth analysis. For surface analysis, the time of exposure seemed to influence more the recovering of microorganisms 
on the surface of panels than the tested coating systems. Between 2 and $4 \mathrm{LOG}\left(\mathrm{CFU} / \mathrm{cm}^{2}\right)$ were recovered after three and nine months of exposure, whatever the coating system. Between 0 and 3 LOG $\left(\mathrm{CFU} / \mathrm{cm}^{2}\right)$ were recovered after six and 12 months whatever the coating system. However, the two semi-transparent coating systems were less affected by fungal contamination, which confirmed the visual assessments.

For in-depth analysis, the recovery of microorganisms increased with the time of exposure. After 12 months, the two semi-transparent coating systems were significantly less affected by fungal contamination (1 LOG $\left.\left(\mathrm{CFU} / \mathrm{cm}^{2}\right)\right)$ than the clear coating systems $\left(3 \mathrm{LOG}\left(\mathrm{CFU} / \mathrm{cm}^{2}\right)\right)$. The results demonstrated that the growth of microorganisms was lower when pigments were present in the coatings.

\subsection{Fungal Identification}

The main fungi isolated after fungal enumeration were identified to analyze the diversity of microorganisms able to develop on the four tested coating systems after 3, 6, 9, and 12 months of exposure. Results are shown in Figure 6.

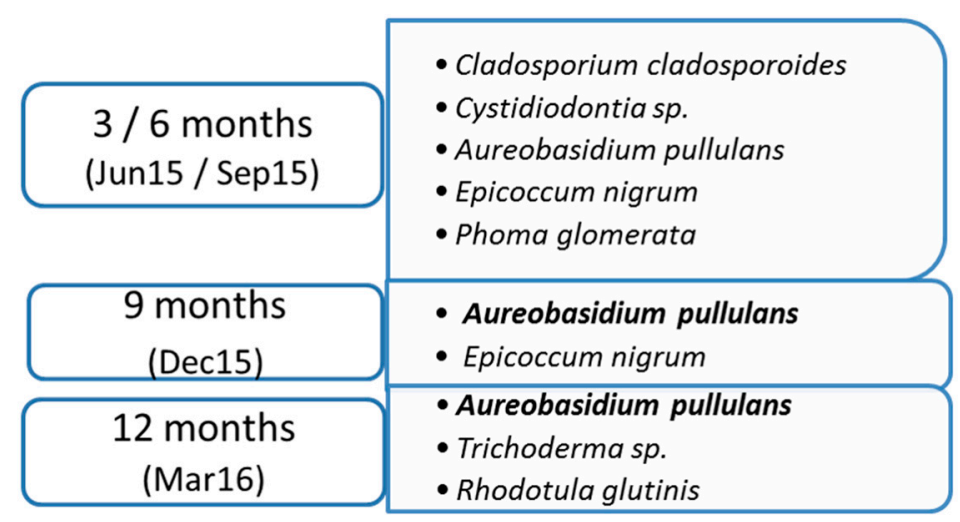

Figure 6. The main fungal species identified after 3, 6, 9, and 12 months of exposure on coated panels (south exposure at $45^{\circ}$ ). Species in bold were predominantly identified.

After three and six months of exposure, several fungal species were identified, mainly present in the environment. After nine and 12 months of exposure, the diversity of the fungal species significantly decreased, and the blue stain fungus Aureobasidium pullulans became dominant. This result also demonstrated that when Aureobasidium pullulans becomes dominant, the diversity of other fungal species decreases. This result was consistent with the visual assessments of fungal growth (Figures 2 and 3), which showed an increase in the area and the intensity of fungal growth after nine and 12 months of exposure.

\subsection{Influence of Cardinal Direction and Surfaces Inclination on Fungal Growth}

Results obtained with samples exposed on the MFER are presented in the following figures.

After three months, only the ICP clear in two and three coats exposed at $45^{\circ}$ north displayed some blue stain (mean area $=1$ ). All other surfaces were not disfigured by visible fungal growth.

The results after six months are shown in Figures 7 and 8 for the area and intensity of blue stain, respectively. They show that the pigmented coating systems were less prone to blue stain growth than the clear coating systems. The surfaces inclined at $45^{\circ}$ showed more blue stain than the vertical surfaces. Samples exposed to south were less prone to blue stain development.

The results after nine months are shown in Figures 9 and 10 for the area and intensity of blue stain, respectively. The same trends than after six months were observed. For the surfaces inclined at $45^{\circ}$, the lowest development of blue stain was for samples exposed to south. 
For some orientations, an additional coat reduced the amount of blue stain. This was clearly the case for the west and east directions. For the north orientation, the results were similar for the two and three coat-applications for both coatings, demonstrating that these surfaces were insufficiently protected. In this case, a fourth coat could probably reduce wetness, and therefore blue stain development.

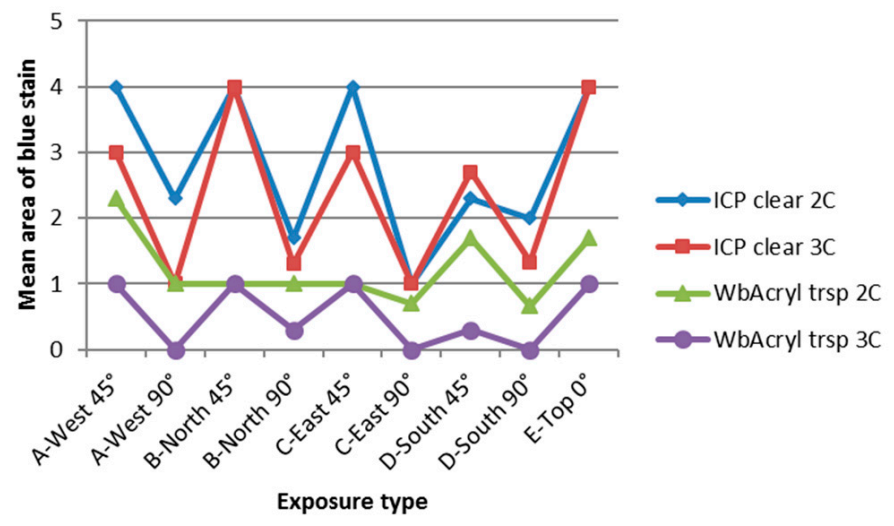

Figure 7. Mean area of blue stain after six months of exposure (February 2016) using the MFER.

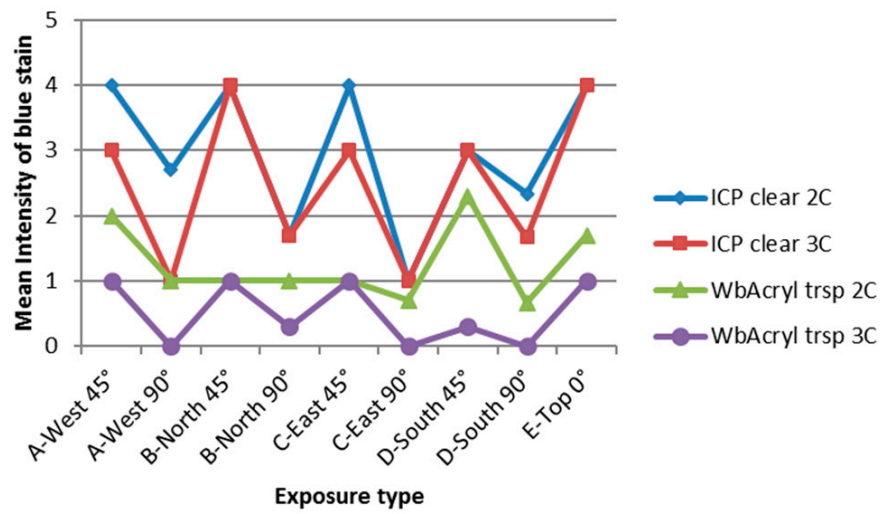

Figure 8. Mean intensity of blue stain after six months of exposure (February 2016) using the MFER.

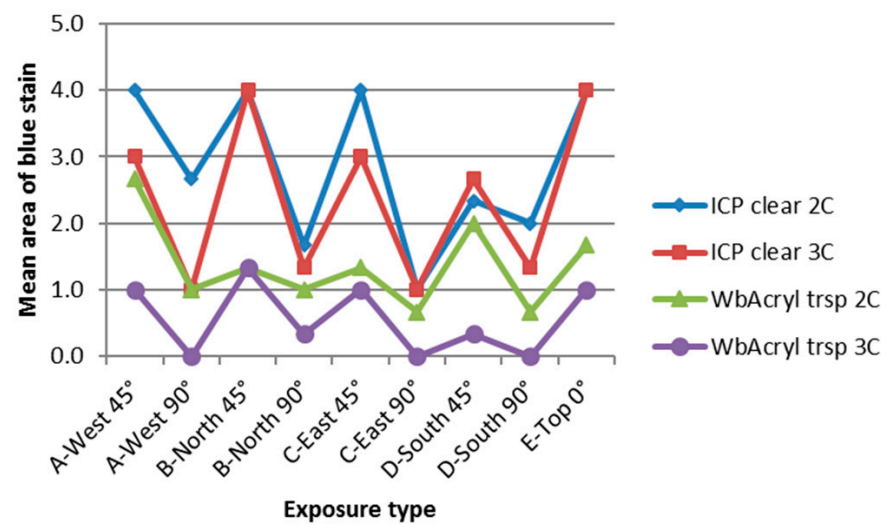

Figure 9. Mean area of blue stain after nine months of exposure (May 2016) using the MFER.

Results after 12 months of exposure are summarized in Figures 11 and 12 for the mean area and the mean intensity of blue stain, respectively. 


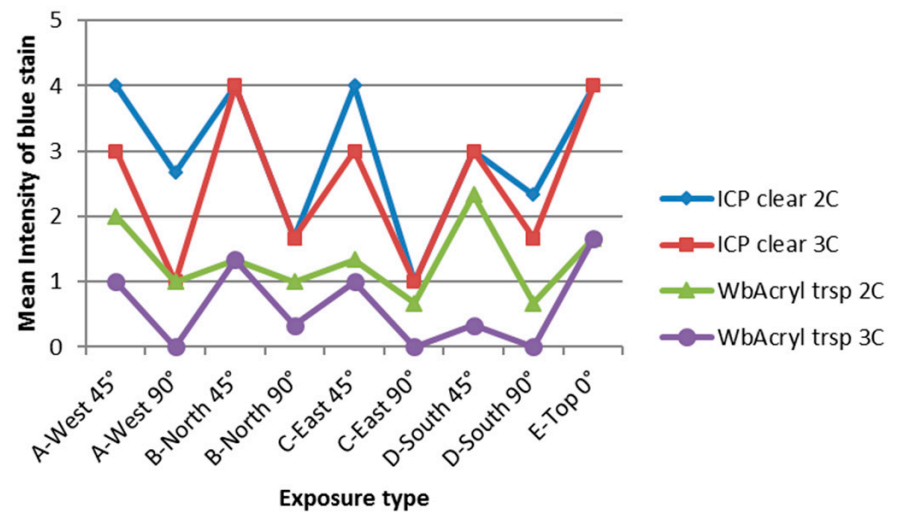

Figure 10. Mean intensity of blue stain after nine months of exposure (May 2016) using the MFER.

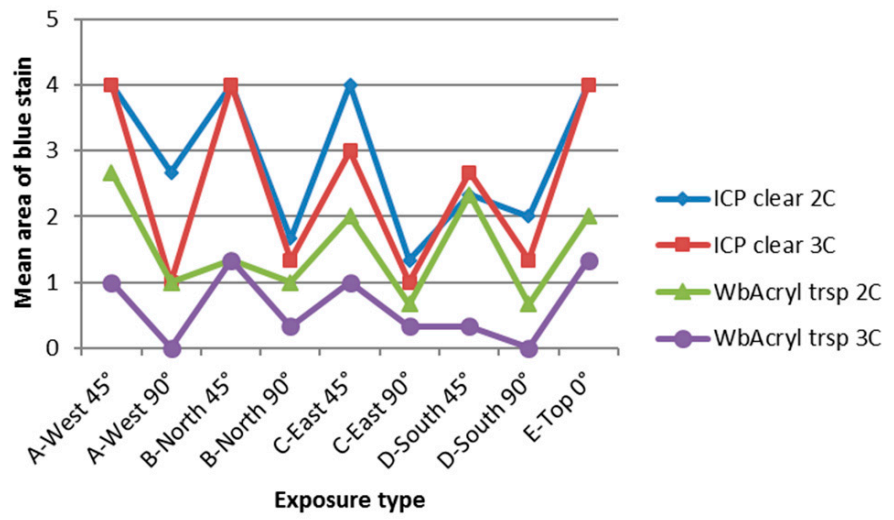

Figure 11. Mean area of blue stain after 12 months of exposure (August 2016) using the MFER.

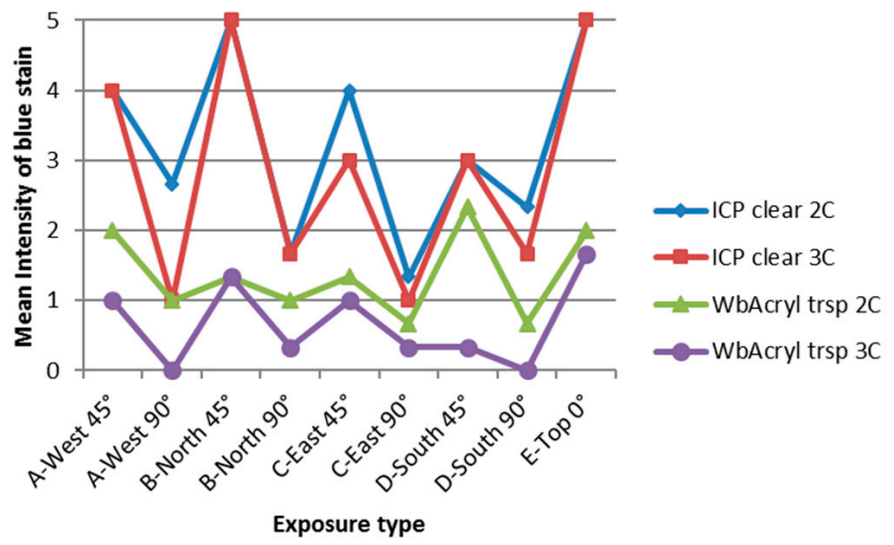

Figure 12. Mean intensity of blue stain after 12 months of exposure (August 2016) using the MFER.

For the clear ICP (two and three coats), the worst cases (highest area and highest intensity) were for samples exposed to north $45^{\circ}$ and at the top of the MFER. Samples exposed to west $45^{\circ}$ were also prone to a lot of blue stain. For such exposures, results were similar for the two and three coat-applications. The disfigurement of samples depending on orientation and inclination were in good agreement with the variation of the moisture content on the MFER, as shown in Figure 13. This figure also shows that all surfaces inclined at $45^{\circ}$ were wetter than those exposed vertically.

For the semi-transparent acrylic coating in two coats, the worst case was for samples exposed at $45^{\circ}$ west. An additional coat led to less blue stain for this direction and angle of exposure, demonstrating better protection of surfaces from wetness. 
The quantity of cracks in the coating systems, assessed after 12 months of exposure, is shown in Figure 14. It shows that cracking was influenced by cardinal direction and the angle of exposure.

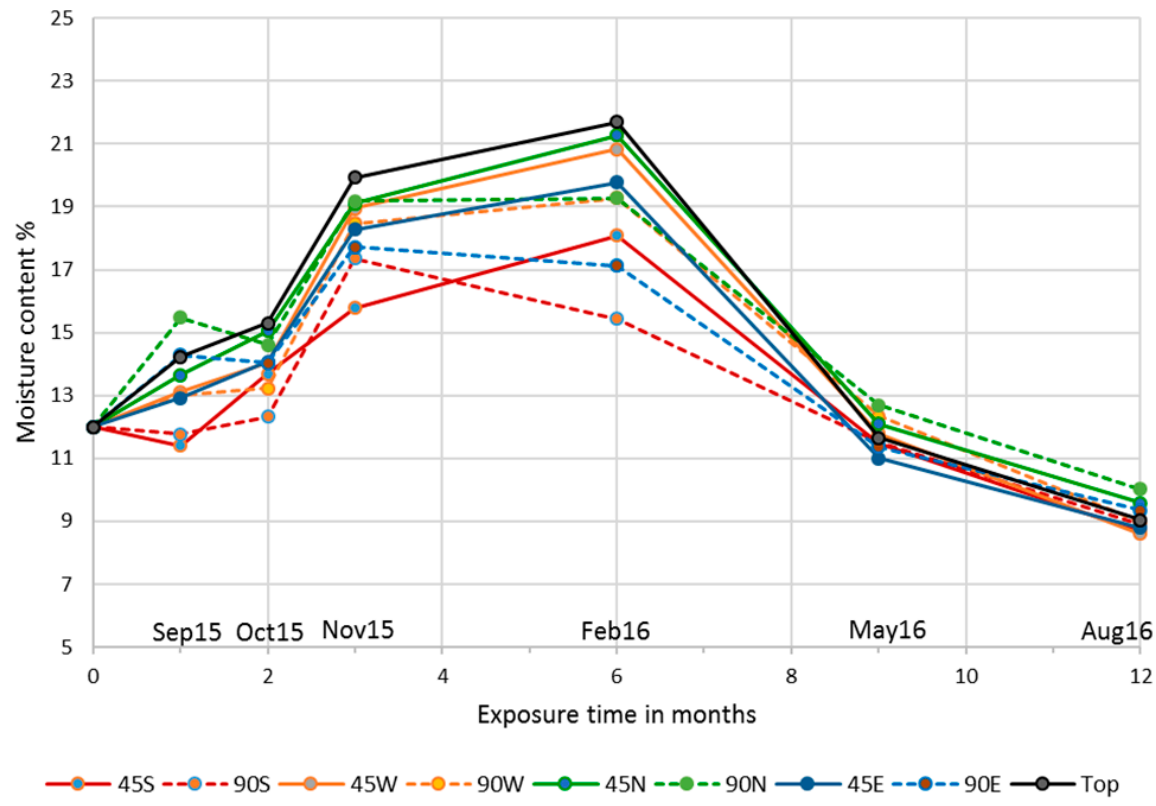

Figure 13. Influence of cardinal direction and the angle of exposure on the moisture content of samples coated with the ICP clear (two coats) exposed on the MFER.

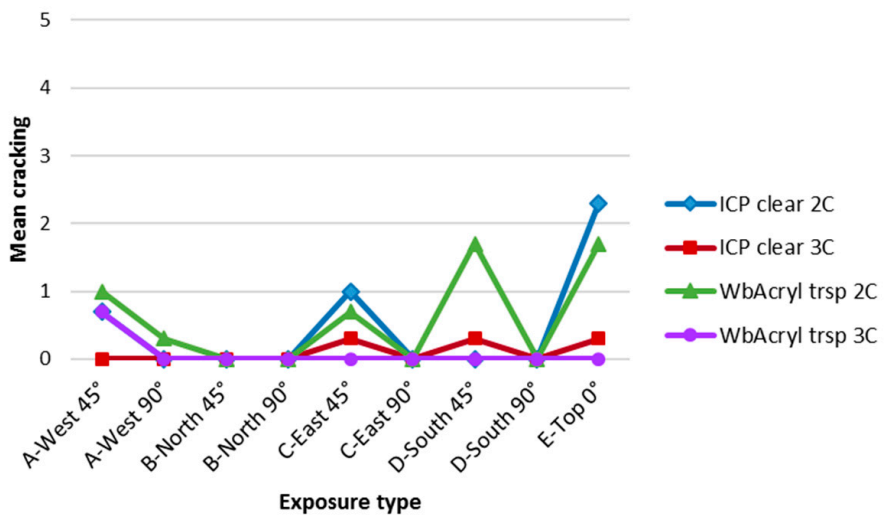

Figure 14. Influence of cardinal direction and the angle of exposure on coating cracking after 12 months of exposure using the MFER.

The comparison of Figure 14 with Figures 11 and 12 (respectively area and intensity of blue stain fungi) clearly shows that the development of blue stain fungi was not linked with the development of cracking. Some surfaces were free of visible cracking, but they displayed significant blue staining. For example, the clear ICP in two coats had no cracking for surfaces exposed to north $45^{\circ}$ which displayed the highest ratings for both the area and intensity of blue stain fungi. The clear ICP in two coats displayed cracking for surfaces exposed to west $45^{\circ}$, east $45^{\circ}$, and at the top of the MFER. Cracking was not observed on the vertical surfaces; however, blue stain fungi were observed.

The increase in coating thickness due to a third coat clearly reduced the cracking score of the clear ICP. For the surfaces exposed horizontally, cracking was reduced from 2.3 to 0.3 , due to the additional layer of the ICP clear.

For the semi-transparent acrylic coating in two coats, the highest cracking score of 1.7 was for surfaces exposed to south $45^{\circ}$ and horizontally. Surfaces exposed to north did not show any visible cracking, but had some blue stain fungi. The addition of a third coat clearly led to a decrease in 
cracking development. All surfaces, except those exposed to west $45^{\circ}$, were free of cracking, but most of them displayed some blue stain fungi (Figures 11 and 12).

\section{Discussion}

Results have shown that fungal growth on coatings exposed for one year mainly consisted of blue stain fungi, as was already reported by some authors $[4,7,16]$. Fungal growth was significantly influenced by coating pigmentation, which confirms the findings of other authors [4,8-10]. Significantly lower fungal growth was observed on the pigment-containing coatings, compared with their pigment-free versions. Despite the clear solventborne coating (ICP clear) including a higher amount of biocide, it was more susceptible to blue stain than the pigmented recipe (ICP strsp). In the waterborne coatings, the amount of biocide was the same, whether the coating was pigmented or not. However, the pigmented waterborne coating was less prone to blue stain development. Several phenomena can contribute to this effect. Pigments lead to an increase in surface temperature, which decreases the time of the wetness of the samples. Furthermore, pigments also protect biocides from UV degradation [17], which result in better protection from fungal growth for pigmented coatings. The pigments included in coatings were iron oxides. Iron has shown to have a toxic effect on some fungi $[18,19]$. Therefore, iron oxide pigments may have a biocidal effect on blue stain fungi. Pigmented and clear coatings could also display differences in surface acidity, which could contribute to the lower fungal growth on pigmented coatings.

The results of fungal enumeration were clearly different for surface and in-depth analysis of samples (Figures 4 and 5). At sample surfaces, the number of colonies versus exposure time was in good agreement with seasonal fluctuations: it was higher in winter for the wetter months and lower during summer. The seasonal influence on the number of colonies within the first four millimeters of the samples was less clear. Kržišnik et al. reported seasonal variation in color changes of uncoated wood for samples exposed outdoors in Slovenia for four years [20]. According to the authors, the most important reason for seasonal fluctuations was related to fungal melanin, with its formation on one hand being countered by bleaching on the other. In our study, uncoated wood samples, as well as samples covered with the clear coatings showed a gradual increase in the intensity of blue staining over the year (Figure 3). The intensity of fungal growth (EN 16492 ) was directly related to color changes. The seasonal fluctuations of color changes described by Kržišnik et al. were therefore not visible in our results.

Solar radiation is one of the main agents causing the degradation of organic materials exposed outdoors. Therefore, weathering studies usually focus on maximizing solar radiation. Test panels were exposed facing the equator (i.e., facing south in the northern hemisphere), at an angle to the horizontal equal to the latitude of the site where they are exposed, receive the greatest total solar energy of any possible fixed orientations [21]. Practical considerations, such as having similar water run-off from specimens in different localities, have often resulted in exposure racks facing the equator at an angle of $45^{\circ}$ to the horizontal, regardless of the latitude of the locality [21]. As the latitude of Bordeaux is $45^{\circ}$, the maximum dose of solar radiation was received for samples facing south at $45^{\circ}$. This orientation and inclination clearly underestimated the issue of fungal growth on coated wood. The MFER demonstrated a wider range of natural weathering behavior than traditional exposure racks inclined at $45^{\circ}$ facing south. It has been shown that the worst cases (highest area and the intensity of blue stain fungi) were for samples with the clear coating exposed to north $45^{\circ}$, and at the top of the MFER. For such exposures, results were similar between the two and three coats applications demonstrating insufficient coating thickness for these surfaces. These orientations and inclinations also led to the highest moisture content in the samples. A study that compared two sites in Norway showed that highest mold rating was detected facing north at one location, and facing south at the other. The authors concluded that the effect of cardinal direction on mold growth can vary from site to site [22]. This finding shows that the prevailing rain should be taken into consideration when orienting 
exposure racks for trials related to fungal growth. Wind driven-rain will increase surface wetness after heavy precipitation, and therefore encourage fungal growth.

Cracking of coatings is an indication they lack sufficient flexibility to accommodate the surface strains that develop when wood swells and shrinks [1]. Cracking is often selected to indicate the end of the service life of coatings, and the need for maintenance [23,24]. Coating cracking will lead to higher fluctuations of wood moisture content, especially during winter [25], which encourages colonization by staining fungi. Our results have shown that the growth of blue stain fungi was not due to cracking development, and could start before visible cracking was noticed. This finding is noteworthy, and shows that special attention should be given to the assessment of blue stain fungi during weathering trials.

\section{Conclusions}

Results have shown that fungal growth on coatings exposed outdoors mainly consisted of blue stain fungi. Fungal growth was significantly influenced by coating pigmentation, cardinal direction, and the angle of exposure.

This study has clarified the sequence between fungal growth and cracking development. It was shown that blue stain fungi started to grow before the cracking of coatings was noticed. The hyphae of such fungi can lead to pinholes forming in the coating system. Therefore, the service life of coating systems may be dramatically shortened because pinholes can increase water uptake of wood samples. This will lead to higher fluctuations in wood moisture content, dimensional variations of the substrate and coating cracking. We conclude that the mandatory performance criteria of coatings described in EN 927-2 should include fungal growth as well.

Coatings manufacturers commonly use weathering trials to develop new products. In the northern hemisphere, racks facing south and inclined at $45^{\circ}$ are used. This orientation clearly underestimates the issue of fungal growth. Surfaces exposed to north and inclined at $45^{\circ}$ displayed more blue stain, and provided additional information on the coating service life. Dry-film biocides are used to make the coating system durable. In Europe, as a result of the Biocidal Products Regulation, the number of biocides used to protect dry-films has declined. Furthermore, the development of new active substances has almost completely stopped, due to the cost and complexity of registering substances. Therefore, there is a strong need for alternatives and innovation in dry-film protection coating systems. Any means of reducing the surface wetness should be considered when developing coatings. Coating pigmentation modifies the surface temperature, and therefore decreases surface wetness and fungal growth. Increasing the coating thickness with the application of additional layers will result in the better protection of surfaces exposed to critical cardinal directions. Any additives that can reduce moisture in the coating film could also contribute to reduce fungal growth on coated wood.

Author Contributions: Conceptualization, L.P.; Methodology, L.P. and M.M.; Validation, L.P. and M.M.; Formal Analysis, L.P. and M.M.; Investigation, L.P., C.R. and M.M.; Resources, C.R. and M.M.; Data Curation, L.P.; Writing-Original Draft Preparation, L.P. and M.M.; Writing-Review \& Editing, L.P.; Visualization, L.P.; Supervision, L.P.; Project Administration, L.P.; Funding Acquisition, L.P.

Funding: This research was funded within the project SERVOWOOD by the Seventh Framework Programme (FP7/2007-2013) of the European Commission (No. FP7-SME-2013-606576).

Acknowledgments: Contributions to the project from all consortium members are acknowledged. Special thanks to Teknos Drywood B.V. (The Netherlands) for providing the two acrylic coatings, and to the Paint Research Association (United Kingdom) for the alkyd coatings.

Conflicts of Interest: The authors declare no conflict of interest. 


\section{References}

1. Evans, P.D.; Haase, J.G.; Shakri, A.; Seman, B.M.; Kiguchi, M. The search for durable exterior clear coatings for wood. Coatings 2015, 5, 830-864. [CrossRef]

2. Jellison, J.; Goodell, B.; Daniel, G. The biology and microscopy of building molds: Medical and molecular aspects. In Development of Commercial Wood Preservatives: Environmental, and Health Issues; Schultz, T.P., Militz, H., Freeman, M.H., Goodell, B., Nicholas, D.D., Eds.; American Chemical Society: Washington, DC, USA, 2008.

3. Cogulet, A.; Blanchet, P.; Landry, V.; Morris, P. Weathering of wood coated with semi-clear coating: Study of interactions between photo and biodegradation. Int. Biodeterior. Biodegrad. 2018, 129, 33-41. [CrossRef]

4. De Meijer, M. Review on the durability of exterior wood coatings with reduced VOC-content. Prog. Org. Coat. 2001, 43, 217-225. [CrossRef]

5. Regulation (EU) No 528/2012 of the European Parliament and of the Council of 22 May 2012 concerning the making available on the market and use of biocidal products. Off. J. Eur. Union 2012, L167, 1-123.

6. Jensen, H.; Sandve, M.; Lystvet, S.M. Exterior paint for the future-Will there be any dry-film preservatives left? In Proceedings of the International Research Group on Wood Protection, 48th Annual Meeting, Ghent, Belgium, 4-8 June 2017.

7. Gaylarde, C.G.; Morton, L.H.G.; Loh, K.; Shirakawa, M.A. Biodeterioration of external architectural paint films-A review. Int. Biodeterior. Biodegrad. 2011, 65, 1189-1198. [CrossRef]

8. Gobakken, L.R.; Vestøl, G.I. Mould growth on spruce claddings and the effect of selected influencing factors after 4 years of outdoor testing. In Proceedings of the International Research Group on Wood Protection, 43rd Annual Meeting, Kuala Lumpur, Malaysia, 6-10 May 2015.

9. Gobakken, L.R.; Westin, M. Surface mould growth on five modified wood substrates coated with three different coating systems when exposed outdoors. Int. Biodeterior. Biodegrad. 2008, 62, 397-402. [CrossRef]

10. Van Acker, J.; Stevens, M.; Brauwers, C.; Rijckaert, V.; Mol, E. Blue stain resistance of exterior wood coatings as a function of their typology. In Proceedings of the International Research Group on Wood Protection, 29th Annual Meeting, Maastricht, The Netherlands, 14-19 June 1998.

11. EN 927-2 Paint and Varnishes_Coating Materials and Coating Systems for Exterior Wood_Part 2: Performance Specification; European Committee for Standardization: Brussels, Belgium, 2014.

12. EN 927-3 Paint and Varnishes_Coating Materials and Coating Systems for Exterior Wood-Part 3: Natural Weathering Test; European Committee for Standardization: Brussels, Belgium, 2012.

13. EN 16492 Paint and Varnishes-Evaluation of the Surface Disfigurement Caused by Fungi and Algae on Coatings; European Committee for Standardization: Brussels, Belgium, 2014.

14. Gardes, M.; Bruns, T.D. ITS primers with enhanced specificity for basidiomycetes-application to the identification of mycorrhizae and rusts. Mol. Ecol. 1993, 2, 113-118. [CrossRef] [PubMed]

15. EN ISO 4628-4 Paints and Varnishes-Evaluation of Degradation of Coatings-Designation of Quantity and Size of Defects, and of Intensity of Uniform Changes in Appearance-Part 4: Assessment of Degree of Cracking; European Committee for Standardization: Brussels, Belgium, 2003.

16. Hansen, K. Molds and moldicide formulations for exterior paints and coatings. In Development of Commercial Wood Preservatives: Environmental, and Health Issues; Schultz, T.P., Militz, H., Freeman, M.H., Goodell, B., Nicholas, D.D., Eds.; ACS Symposium Series; American Chemical Society: Washington, DC, USA, 2008.

17. Urbanczyk, M.M.; Bester, K.; Borho, N.; Schoknecht, U.; Bollmann, U.E. Influence of pigments on phototransformation of biocides in paints. J. Hazard. Mater. 2019, 364, 125-133. [CrossRef] [PubMed]

18. Anahid, S.; Yaghmaei, S.; Ghobadinejad, Z. Heavy metal tolerance of fungi. Sci. Iran. 2011, 18, 502-508. [CrossRef]

19. Wiśnicka, R.; Krzepiłko, A.; Wawryn, J.; Biliński, T. Iron toxicity in yeast. Acta Microbiol. Pol. 1997, 46, 339-347. [PubMed]

20. Kržišnik, D.; Boštjan, L.; Thaler, N.; Humar, M. Influence of natural and artificial weathering on the colour change of different wood and wood-based materials. Forests 2018, 9, 488. [CrossRef]

21. Ballantyne, E.R. The effect of orientation and latitude on the solar radiation received by test panels and fences during weathering studies. Build. Sci. 1974, 9, 191-196. [CrossRef] 
22. Gobakken, L.R.; Vestøl, G.I. Effects of microclimate, wood temperature and surface colour on fungal disfigurement on wooden claddings. In Proceedings of the International Research Group on Wood Protection, 43rd Annual Meeting, Kuala Lumpur, Malaysia, 6-10 May 2012.

23. Forsthuber, B.; Grüll, G.; Arnold, M.; Podgorski, L.; Bulian, F. Service life prediction of exterior wood coatings. In Proceedings of the 5th International Conference on Processing Technologies for the Forest and Bio-based Products Industries, Freising, Germany, 20-21 September 2018.

24. Grüll, G.; Truskaller, M.; Podgorski, L.; Bollmus, S.; Tscherne, F. Maintenance procedures and definition of limit states for exterior wood coatings. Eur. J. Wood Wood Prod. 2011, 69, 443-450. [CrossRef]

25. Grüll, G.; Truskaller, M.; Podgorski, L.; Bollmus, S.; De Windt, I.; Suttie, E. Moisture conditions in coated wood panels during 24 months natural weathering at five sites in Europe. Wood Mater. Sci. Eng. 2013, 8 , 95-110. [CrossRef]

(C) 2019 by the authors. Licensee MDPI, Basel, Switzerland. This article is an open access article distributed under the terms and conditions of the Creative Commons Attribution (CC BY) license (http://creativecommons.org/licenses/by/4.0/). 